\title{
Panorama atual dos Museus de Educação em Espanha
}

Pauli Dávila Balsera

Luis M. Naya Garmendia

DOI: | 0.265 I 2/museologia.v8i I6.2I I 43

\begin{abstract}
Resumo
A recuperação do patrimônio histórico-educacional na Espanha está experimentando uma fase de crescimento reconhecido. Neste artigo analisamos a emergência dos primeiros museus pedagógicos e escolares, sua situação na Europa e na Espanha e, apontamos algumas características de outros dois tipos de museus que possuem conteúdo educacional, até o momento o seu mapeamento completo não pode ser feito devido ao estado atual da pesquisa em museus. Para isso, partimos de sua dependência institucional, aplicando uma série de categorias: relato de museu, atividades realizadas, tipologia patrimonial, audiências e gestão de museus. A conclusão a que chegamos é que a existência destes museus dá conta, devido à sua extensão territorial e agentes implicados, de um dinamismo exemplar e dos desafios que enfrentam no futuro.
\end{abstract}

\section{Palavras-chave:}

Patrimônio Histórico-Educacional. Espanha. Museus Pedagógicos. Museus Escolares. Museus de Educação.

\begin{abstract}
The recovery of Historical-Educational Heritage in Spain is experiencing a stage of recognized growth. In this article, we analyze the emergence of the first pedagogical and school museums, their situation in Europe and in Spain and, we point out some characteristics of two other types of museums that have educational content, so far their complete mapping cannot be done due to the current state of museum research. To do this, we start from its institutional dependence, applying a series of categories: museum report, activities carried out, patrimonial typology, audiences and museum management. The conclusion we have reached is that the existence of these museums gives full account, due to their territorial extension and implicated agents, of an exemplary dynamism and of the challenges they face in the future.
\end{abstract}

\section{Keywords:}

Historical-Educational Heritage. Spain. Pedagogical museums. School museums. Museums of education.

\section{Resumen}

La recuperación del Patrimonio Histórico-Educativo en España está viviendo una etapa de crecimiento reconocido. En este artículo analizamos el surgimiento de los primeros museos pedagógicos y escolares, su situación en Europa y en España y, apuntamos algunas características de otros dos tipos de museos que tienen contenido educativo, sin que hasta el momento pueda realizarse su cartografía completa debido al estado actual de la investigación museística. Para ello, partimos de su dependencia institucional, aplicando una serie de categorías: relato museístico, actividades que realizan, tipología patrimonial, audiencias y gestión del museo. La conclusión a la que hemos llegado es que la existencia de estos museos da cumplida cuenta, por su extensión territorial $y$ agentes implicados, de una dinamicidad ejemplar y de los retos a los que se enfrentan en un futuro.

\section{Palabras Clave:}

Patrimonio Histórico-Educativo.España. Museos Pedagógicos. Museos Escolares. Museos de la Educación.

I Museo de la Educación de la Universidad del País Vasco/Euskal Herriko Unibertsitatea.pauli.davila@ehu. eus; luisma.naya@ehu.eus. 


\section{Introducción}

La recuperación de la memoria histórico-educativa, en la actualidad, seestá desarrollando a través de la puesta en valor y salvaguarda del patrimonio escolar y pedagógico. En el contexto occidental cada vez es más frecuente encontrar museos escolares, pedagógicos, educativos, del juego, de la infancia, etc., que recuperan el patrimonio histórico-educativo. En esta colaboración queremos mostrar el panorama actual de los museos de la educación en España, para ello nos acercamos al surgimiento de los Museos Pedagógicos, a partir del siglo $\mathrm{XIX}$, y su diferenciación con respecto a los museos escolares, enmarcando las etapas y la evolución de los museos de la educación en Europa.

La situación en España con respecto a los museos de la educación es muy alentadora, en tanto que se han producido iniciativas museísticas que están consolidando sus actividades. Para poder analizar la situación de estos museos nos ha parecido pertinente clasificarlos en función de la diferente dependencia institucional. Así, ante la carencia actual de un museo pedagógico nacional, podemos hablar de un conjunto de museos dependientes de los gobiernos regionales, de museos universitarios, de museos escolares en centros educativos no universitarios y de museos etnográficos o similares con temática educativa. Esta clasificación nos ha permitido realizar una aproximación a una cartografía de los mismos, destacando los indicadores (dimensiones y categorías) que nos parecen más pertinentes para analizar dichos museos: relato museístico, actividades que realizan, tipología patrimonial, audiencias y gestión del museo. La conclusión a la que hemos llegado es que la existencia de estos museos da cumplida cuenta, por su extensión territorial y agentes implicados, de una dinamicidad ejemplar y los retos a los que se enfrentan en un futuro.

\section{I - Surgimiento y primeros museos pedagógicos}

El estudio de los museos pedagógicos tiene dos líneas de dependencia histórica: la primera, el contexto de surgimiento de cada uno de ellos y, la segunda, la tradición museística. En este último sentido, los museos pedagógicos, como cualquier otro tipo de museo, comparte la concepción que definen los museos en general. Por lo que respecta al caso español, la Ley 16/1985 de Patrimonio Histórico Español y el Real Decreto 620/I987, por el que se aprueba el Reglamento de Museos de Titularidad Estatal y del Sistema Español de Museos, definen los museos en la línea proclamada por el Consejo Internacional de Museos (ICOM): «Son museos las instituciones de carácter permanente que adquieren, conservan, investigan, comunican y exhiben para fines de estudio, educación y contemplación conjuntos y colecciones de valor histórico, artístico, científico y técnico o de cualquier otra naturaleza cultural» (artículo 59.3, Ley 16/1985).

No obstante, esta definición ha ido evolucionando a través del tiempo, pudiéndose apreciar que el nuevo concepto de museo contempla a los visitantes como un núcleo central de su concepción, aumentando sus funciones socio-culturales, incorporando nuevos modelos profesionales y trabajando en equipos multidisciplinares. En este artículo no nos referiremos a esta cuestión, que es muy rica y que está ayudando a que los museos pedagógicos vayan adquiriendo criterios museísticos a la hora de presentar sus colecciones escolares, ya que se encuadran mejor en un área de didáctica de los museos. Tan sólo queremos recordar la definición del Consejo Internacional de Museos (ICOM), pues es el 
marco en el que se insertan los museos de la educación, en 2007, que plantea que "un museo es una institución permanente, sin fines de lucro, al servicio de la sociedad y abierta al público, que adquiere, conserva, estudia, expone y difunde el patrimonio material e inmaterial de la humanidad con fines de estudio, educa-

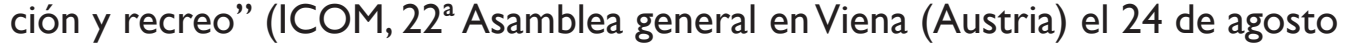
de 2007).

Los antecedentes más inmediatos a la creación de los museos pedagógicos, como es conocido, los encontramos en el siglo XIX, a raíz de las diversas exposiciones universales que, desde la que se celebró en $185 \mathrm{I}$ en Londres, se han ido sucediendo por diversas ciudades del mundo. El concepto de exposición universal contribuyó fuertemente a la difusión política de los logros científicos, tecnológicos e industriales de las potencias mundiales que incorporaron algunas "curiosidades" y elementos etnográficos de lo que, en aquellos años, eran las colonias. Por lo tanto, el surgimiento de los museos, en este contexto, está unido al proceso de industrialización y progreso de la ciencia y de la técnica que se vivía en esa etapa histórica en Europa y donde, además, se hacía muestra pública de los avances. Era como un escaparate donde se mostraban los últimos inventos y progresos de las naciones, con lo que se pretendía también construir unas señas de identidad nacional. En estas exposiciones también algunos centros escolares mostraban sus adelantos pedagógicos al público. Un ejemplo lo tenemos en la congregación de los Hermanos de las Escuelas Cristianas (La Salle) que alardeaba de los premios obtenidos a la mejor maqueta o al mejor material escolar para la enseñanza. Con ello se conseguía mostrar en público los adelantos de las prácticas pedagógicas a través de métodos didácticos innovadores.

Por lo que se refiere al ámbito educativo podemos observar dos aspectos relacionados con ese proceso de construcción nacional: la creación de los sistemas educativos nacionales y la formación de los maestros desde una perspectiva innovadora, que se irá considerando como el elemento más importante en los procesos de aprendizaje. Como correlato de las citadas exposiciones, surgirán los museos con diferentes denominaciones (museo de educación, museo escolar, exposición escolar, museo pedagógico, etc.). En general, estos museos mostraban un conjunto de elementos comunes: biblioteca, legislación educativa, documentos, colecciones de material de enseñanza, mobiliario escolar, etc. Como señala Ruiz Berrio:"se habían montado para dar gusto a los afanes nacionalistas, para estimular el comercio y también para adelantar procedimientos, métodos, máquinas u objetos varios” (Ruiz Berrio, 2003: 59). En la misma línea, García del Dujo (1984), recoge las razones que explican el surgimiento de los museos:

- Las transformaciones políticas y económicas que se producen en Europa que llevan a considerar a la educación como el "factor fundamental en la configuración del nuevo orden liberal-burgués".

-El proceso de institucionalización del sistema escolar primario y la necesidad de mejorar las condiciones pedagógicas e higiénicas.

- Una nueva didáctica que toma las ideas de Rabelais, Comenio, Rousseau y Pestalozzi, haciendo hincapié en las cosas, los objetos y no en las palabras.

A estas razones, con las que coincidimos, podríamos añadir las que apunta Linares (20I2), que complementaban ese contexto que se produce en el mundo occidental:

- La necesidad de construir identidades nacionales acordes con los nuevos Estados nacionales. 
-Las ideas positivistas que acompañaron el proceso de renovación científico-técnica.

- La formación de ciudadanos bajo la lógica de las relaciones de producción capitalista.

No obstante, podemos constatar una diferente denominación de los museos, sus funciones y usos distintos. Nos referimos a los museos pedagógi$\cos$ y a los escolares durante el último tercio del siglo XIX y el siglo XX. En la actualidad, debido a la evolución y la nueva denominación de los museos de la educación, parece haber superado esa diferencia semántica, con una definición donde el rasgo más relevante es ajustarse a una concepción amplia de la educación y el patrimonio histórico-educativo.

\section{I.I- Museo pedagógico versus museo escolar}

Un tema recurrente, cuando intentamos clarificar y definir los museos con un patrimonio escolar o pedagógico, es establecer la diferencia entre lo que es un museo pedagógico y un museo escolar. Entendemos que existe otra denominación más general como es la de museos de la educación, que engloba tanto a los museos pedagógicos como a los escolares, que son los que, mayoritariamente, salvaguardan el patrimonio histórico-educativo. No ocurre lo mismo con los museos etnográficos que, en general, incluyen objetos educativos como complemento a la visión etnográfica. El caso español, en la perspectiva histórica, como otros, es un buen ejemplo para ver la evolución, las características, los usos o sus propios relatos museísticos.Así, en 1882 en España, se creó el Museo de Instrucción Primaria, que cambió su nombre a Museo Pedagógico Nacional en 1894. Este museo pedagógico, como otros similares, surgió como una "apuesta decisiva por el estudio y las mejoras de las condiciones escolares, de los materiales y didáctica de la enseñanza, o el impulso de nuevas teorías pedagógicas" (Martín, 2007: 349), abriendo la primera exposición escolar y, poco después, la convocatoria para la provisión del puesto de Director del Museo. El Museo Pedagógico nació "como respuesta al precario estado en que se encontraba la educación primaria en general y las Escuelas Normales en particular" (García del Dujo, 2012: 28I), y pretendió ser un revulsivo en la formación del profesorado; teniendo claros referentes fuera de las fronteras españolas.

Por otra parte, el surgimiento de este museo debemos enmarcarlo en los trabajos de la Institución Libre de Enseñanza (ILE), con sus planteamientos de innovación pedagógica y la aportación de las corrientes pedagógicas presentes en ese momento en vigor en Europa. No podemos olvidar que el Museo, en esta época, tenía como objetivo la formación del magisterio, y que, según el Real Decreto que lo desarrolló en I882, se definía como "un centro facultativo y exposición permanente donde, en presencia de los mismos objetos, se discutan los problemas enlazados con la instrucción, la educación y el desarrollo corporal del niños [...] donde el público aprenda y se interese en la práctica de las reformas y donde las corporaciones y particulares que funden nuevas escuelas encuentren números modelos que faciliten la empresa de plantearlas". La actividad desarrollada por el Museo (cursos, conferencias, exposiciones, colonias escolares, etc.) desde 1882 hasta 1925, denotaba esa amplitud de objetivos y de públicos diferentes, desde el experto hasta las corporaciones o los particulares. Pero, sobre todo, lo que interesaba resaltar es que el museo pedagógico era el "alma de la renovación pedagógica" impulsada por la ILE (Sánchez Sarto, 1936: 
2192). No obstante, y antes de la reforma de 1932, hay que constatar que el Museo era poco más que una Biblioteca, despareciendo el resto de actividades. En esos años, el reglamento señalaba la formación de colecciones, material escolar, aparatos de proyecciones, establecimiento de laboratorios, formación de cantinas y colonias escolares, etc. Con ello se pretendía restituir al Museo en su antigua significación. No obstante, todavía en 1936 no había logrado recuperar su antiguo esplendor.

En este sentido, y por lo que respecta a la concepción de este museo pedagógico, coincide con lo que se recoge en la edición de 1888 del Diccionario de Pedagogía e Instrucción Primaria de Buisson (Fatalot, 1888: 1982) y que lo define como un centro que abarca, por una parte, una biblioteca de obras sobre educación, de legislación y administración escolares, así como libros clásicos y, por otra, colecciones de material de enseñanza y mobiliario escolar. Entre los museos pedagógicos destacan los de París (actualmente instalado en Rouen), Londres, Bruselas, Viena, etc. Es decir, en el último cuarto del siglo XIX los museos pedagógicos se estaban extendiendo por los diferentes países de Europa a una velocidad extraordinaria y España no estaba al margen de este proceso. Cossío presentaba el Museo como "un museo pedagógico, no un museo escolar [...], llamado a servir a la educación de los maestros más que a la de los niños" (García del Dujo, 2012: 284).

Como vemos, desde los inicios, ya se ve claramente la diferencia entre museos pedagógicos y museos escolares y se puede afirmar que se refieren a realidades diferentes. Así podemos observar que los museos escolares eran dispositivos didácticos construidos por materiales para apoyar la docencia en las aulas. Se encontraban, por lo general, en las escuelas, en un espacio específico o en algún armario del aula y estaban compuestos por colecciones de flora, fauna y minerales de distinta procedencia, modelos para las clases de anatomía, la historia natural, etc., y también comprendían una serie de objetos para ser utilizados en las "lecciones de cosas" (Linares, 20I2). Estos museos están en la misma línea que recogía el diccionario de Buisson, ya que dentro de ellos enmarca las colecciones de todo origen creadas por el maestro destinadas a proporcionar a los niños ideas claras, exactas sobre todo lo que les rodea (Fatalot, I888: 1991). Por lo tanto, parte del material podía ser aportado por los alumnos y docentes, o también adquirido por compra, entre otros, a los museos pedagógicos.

La creación de los museos escolares reforzaba los métodos de trabajo en el aula, estimulando la observación y en algunos casos la experimentación, promoviendo la recolección, ordenación, clasificación y preservación de ejemplares, así, como afirma Xandri Pich (1927:5), "el museo escolar es una de las manifestaciones más interesantes de la vida de la escuela, por ser vivo reflejo de la actividad docente de la misma y de la intensidad y orientación del trabajo en todo centro de educación". Los primeros "museos escolares" estaban formados por una serie de "cajas enciclopédicas" importadas de Francia o Alemania. En este momento la industria y el comercio de material pedagógico y escolar comienza a tener su importancia. Una de las empresas de mayor prestigio fue la Maison Deyrolle², que comercializaba su propia colección que comprendía:

2 Ese negocio era originalmente de su abuelo naturalista: Jean-Baptiste Deyrolle quien abrió la empresa en 183 I en Rue de la Monnaie 23. El padre de Émile, Achille Deyrolle, siguió con el negocio por muchos años y Émile lo llevó adelante desde 1866. La dirección desde I88I (y aún hoy) es rue du Bac 46 de París. Deyrolle se especializó en publicaciones de historia natural y especímenes con taxidermia, minerales, rocas, fósiles, especímenes vegetales, ostras, taxidermia, especímenes microscópicos y microscopios. https://www. youtube.com/watch?v=qHYc5-_lv20 https://www.youtube.com/watch?v=wbagWtzpSRQ 
dos series de cuadros de ciento diez cartones, con excelentes grabados y 700 muestras. Estos cuadros presentaban serios inconvenientes: los títulos y las descripciones estaban en francés, los ejemplares de zoología y botánica eran, en su gran mayoría, exóticos y tenían un precio elevado. Sus catálogos son una buena muestra de hasta donde se había innovado y qué modelos podían utilizarse. Una parte importante de ese material posteriormente se traducirá del francés a otros idiomas, fomentando su expansión, llegando así no sólo a otros países europeos, sino a Latinoamérica o a las colonias francesas. Xandri Pich (1927:6) muestra su reparo a estas colecciones comercializadas por la industria ya que "no responden, de ordinario, aparte de su excesivo coste, a las necesidades de la escuela ni a los fines de la misma", ya que, además, no debemos de pensar en un museo que sea uniforme ya que "sólo el maestro, utilizando sus propios recursos, es el llamado a realizar la obra en cada caso concreto".

El concepto de museo escolar es dinámico, contrariamente a lo que define al museo pedagógico, que es mucho más estático y para uso del profesorado. Así, Sánchez Sarto (1936: 220I) lo define diciendo que "el museo escolar está constituido por el conjunto de elementos demostrativos y comprobativos de que dispone la escuela para hacer viva, objetiva y científica la enseñanza", lo que nos muestra una diferencia profunda entre "museo" y "depósito de material". Por lo tanto, el autor defiende un museo escolar que sea "en cierto sentido, opuesto al concepto del museo en general, ya que el museo es el lugar donde se catalogan y exponen objetos representativos (...) mientras que el museo escolar debe ser un espacio vivo y flexible capaz de estimular el interés infantil, el conocimiento o la actividad”. Queda patente, en esta clara definición, que la opción de utilizar con distinto significado la palabra museo es para darle un nuevo sentido a los museos pedagógicos estáticos y con escasa dinamicidad y participación del alumnado. La defensa de la participación en aquella época no era habitual, como ocurre ahora con las nuevas concepciones museísticas, que hacen hincapié en este importante elemento. Todavía en la primera edición de 1960 del Diccionario de Pedagogía de Lorenzo Luzuriaga continúa manteniendo esta definición, pues no en vano, ambas definiciones están tomadas de la obra de Xandri Pich (1927), quien insiste en que los museos escolares deben ser "fruto de la labor escolar y a su vez medio para hacer más eficiente ésta... y deben ser producidos y recogidos por los alumnos en sus clases, talleres, excursiones, etc." (Luzuriaga, 1960, 269). El caso de Portugal es demostrativo de esa definición, cuando en su legislación en I 884 proponía la apertura de un "museo escolar" en cada escuela, así como la creación de museos escolares en todas las unidades de formación del maestro. En España, el Real Decreto de 2 de septiembre de 1902, que organizaba las Juntas Locales de Instrucción Pública, les adjudicaba, en su artículo 25, la tarea de "fomentar la creación y el desarrollo de los museos escolares, con los objetos que se recojan en los paseos instructivos que los alumnos realicen bajo la dirección de los maestros, remitiendo los ejemplares sobrantes a la Junta Provincial para que pueda distribuirlos entre otras Escuelas de la provincia que carezcan de ellos"

Hay una clara delimitación entre lo que eran los museos pedagógicos y los museos escolares, siguiendo el Diccionario de Pedagogía de Luis Sánchez Sarto (1936). Como hemos visto, el Museo Pedagógico (y por antonomasia el Museo Pedagógico Nacional) y los museos escolares, cumplían funciones diferentes y estaban focalizadas en públicos diferentes: maestros o alumnos. Por lo tanto, ya en esta primera etapa de los museos puede apreciarse este doble sentido que tienen los museos y las funciones diferentes a las que tienen que 
atender, los espacios que deben ocupar, los materiales que deben acoger, etc. Podríamos decir que los museos pedagógicos surgieron con el objetivo de atender unas necesidades de formación del magisterio, mientras que los museos escolares iban dirigidos a la formación y aprendizaje del alumnado. Tanto uno como otro se convirtieron en herramientas útiles para el aprendizaje, la renovación pedagógica y su complementariedad con la escuela.

En este momento, para nosotros, un museo escolar debe de tener en cuenta tanto el instrumental didáctico que se ha utilizado en la escuela (libros, aparatos científicos, muebles, etc.), como la escenificación del propio proceso de enseñanza aprendizaje y las costumbres y usos que se daban en la escuela y en relación con ella en cada momento histórico. Por lo tanto, los museos escolares deben recoger todos aquellos materiales que conforman la cultura escolar (Juliá, 200I).

Por otra parte, la evolución de los museos en Europa y América ha seguido un proceso más o menos similar, donde después de los orígenes señalados, se aprecia una larga etapa que va desde el último tercio del siglo XIX hasta el primer tercio del siglo $X X$.Algunos autores prefieren hacer coincidir esa etapa con los años 40 de ese mismo siglo (Linares, 2012 y Carrillo y otros, 20I2). No podemos olvidar que en 1946 la UNESCO patrocinó la creación de la Oficina Internacional de Museos, que podría marcar mejor el inicio de una nueva etapa en el sentido de que desde ese momento comenzaron a producirse innovaciones con relación a la presentación, conservación, funciones, etc. de los museos.A modo de síntesis de esta evolución, podemos ver las etapas en la siguiente tabla:

Tabla I- Evolución de los museos escolares/pedagógicos y de la educación

\begin{tabular}{|l|l|l|}
\hline Periodo & & Características \\
\hline 1850-1878 & Antecedentes & $\begin{array}{l}\text { - Primeras exposiciones sobre materiales } \\
\text { y métodos educativos } \\
\text { - Incipientes colecciones educativas }\end{array}$ \\
\hline I878-1931 & Periodo de efervescencia & $\begin{array}{l}\text { - Apertura generalizada de museos na- } \\
\text { cionales, regionales, etc. para musealizar } \\
\text { la educación } \\
\text { - Museos escolares como exposición de } \\
\text { medios didácticos }\end{array}$ \\
\hline 193I-1986 & Periodo de crisis y revitali- & $\begin{array}{l}\text {-Cierre de museos } \\
\text {-Derivación de proyectos museísticos a } \\
\text { centros de investigación } \\
\text {-Recuperación museística sobre el patri- } \\
\text { monio educativo }\end{array}$ \\
\hline 1986-Actualiad & Periodo de expansión & $\begin{array}{l}\text {-Apertura o reorientación de los proyec- } \\
\text { tos museológicos, con tendencia a mu- } \\
\text { sealizar la memoria educativa } \\
\text {-Creación de redes museísticas } \\
\text {-Puesta en marcha de museos virtuales. }\end{array}$ \\
\hline
\end{tabular}

\section{2.- Los museos de la educación en Europa}

El panorama museístico sobre la educación en Europa es muy diverso, tanto en cuanto a sus denominaciones (museos escolares, museos pedagógicos, museos de la escuela, museos de la educación, colecciones histórico-escolares, etc.), como en lo relativo a su dependencia institucional (gobiernos, universi- 
dades, asociaciones, etc.), su gestión, los públicos visitantes, sus exposiciones, etc. Opinamos que el término de museos de la educación es el más adecuado por su globalidad, al incluir todo tipo de museos y/o colecciones del ámbito educativo. Desde el punto de vista numérico los datos son divergentes según las fuentes que utilicemos. En 2004, al menos, existían 442 instituciones de este tipo censadas en los diferentes países de Europa (Peña y otros 2004). En este censo Alemania figuraba a la cabeza con 103 centros, Suecia tenía 64, Francia 46, Austria 38, España 36, Noruega 33, Gran Bretaña 28 y Suiza I5. Estos datos hay que revisarlos al alza, a medida que se van conociendo mejor las situaciones particulares de cada país. Sólo como ejemplo de los cambios que se han producido, podemos ver que, en Francia, en 2016, había censados 82 museos de la escuela de dependencia comunal, 76 escuelas representadas en museos de artes y tradiciones populares y 6 fondos documentales y 6 museos de escuelas especializadas, sin olvidar la existencia de un Museo Nacional en Rouen, lo que hace un total de 170 centros (Mieussens, 20 I8). En Italia, asimismo, hay, al menos 50 museos, que se pueden clasificar en museos escolares (29), salas-museo (9), escuelas-museo (8), exposiciones permanentes (3) y museos pedagógicos (I) (Ascenzi, Brunelli y Meda, 20I8).

Por lo tanto, se pone de manifiesto que, según el criterio que se utilice, a la hora de definir este tipo de museo su número varía. A ello no contribuye que el ICOM incorpore a estos museos en la categoría de "Museos de ciencias sociales y servicios sociales", junto con los museos de justicia y policía, por ejemplo. En el caso español es también sorprendente que el Ministerio de Cultura no recoja una categoría específica donde puedan ser incluidos estos museos. Esta situación nos está indicando la necesidad de establecer una tipología de museos escolares, pedagógicos y de la educación, para poder comparar museos homologables, sobre todo, en cuanto a su localización y dependencia institucional. Hay que destacar que el criterio de dependencia institucional es válido en cuanto que otorga a los museos una estabilidad y una financiación que permite el desarrollo de sus actividades. Un trabajo clave para entender la situación de los museos de la educación es el de Myriam Boyer (2009), en el que, a través de un estudio de 29 museos de la educación de 20 países de Europa, da cuenta de la diversidad de colecciones y presentaciones museográficas.

Por otra parte, tanto en España como en Europa y América (Ruiz Berrio, 2006), los museos han venido esforzándose concienzudamente por favorecer la construcción de la perspectiva histórico- educativa a través de la conservación y puesta en valor de la escuela como bien musealizable. En los últimos años diferentes instancias políticas y universitarias están desarrollando importantes iniciativas museísticas, orientadas a conservar, exponer y difundir nuestro patrimonio educativo. Actualmente, en el caso de España, podemos cuantificar más de 60 iniciativas museístico pedagógicas de diversa índole, carácter, tamaño y repercusión (Álvarez, 2016), además de las reconocidas colecciones de materiales escolares, procedentes de iniciativas particulares. En la última década se han realizado importantes estudios sobre el museismo pedagógico y el patrimonio histórico-educativo (Escolano y Hernández, 2002; Escolano, 2007; Juan, 2008; Moreno, 2009 y 20I5; Meda, 2010; Ruiz Berrio, 20l0; López, 20II; Mogarro, 20I5; Meda y Badanelli, 20I5), lo que hace que España ocupe un lugar reconocido entre aquellos países que vienen poniendo un especial interés en la reconstrucción histórica material e inmaterial de la memoria de la educación.

Al margen de esta situación es importante resaltar, como lo hace Boyer (2009 y $20 \mathrm{II}$ ) los aspectos cualitativos para poder conocer la gestión, el trata- 
miento de las colecciones y la valorización y difusión, además de los diferentes tipos de exposiciones museísticas, permanentes o temporales. En este sentido, queremos resaltar uno de los aspectos que nos parece clave y que también es objeto de este artículo, nos referimos a lo que Boyer denomina "Contenus" y "Mise en espace" de estos museos y que, en nuestro trabajo, denominamos "relato museístico"; es decir, la narración sobre la que se basa la presentación de las exposiciones, los objetos, las aulas, etc. y que, en definitiva, es lo que otorga un determinado tipo de identidad a cada uno de los museos. En este sentido, como plantea esta autora, los campos temáticos se basan en cuatro categorías de patrimonio:

a)Escolar: conjunto de los elementos materiales para uso individual o colectivo, relacionados con el alumno, el profesor o más ampliamente con la clase, así como con el sistema de organización y contenido de las enseñanzas;

b)Educativo: vida cotidiana de los escolares; infancia, juventud y vida familiar y juegos y juguetes,

c) Intangible: archivos orales y audiovisuales que conservan testimonios relacionados con la educación, y

d)Construido: conjunto de bienes culturales inmuebles que han tenido un uso educativo.

Por supuesto las dos primeras categorías (escolar y educativo) predominan sobre el resto. De la misma manera, en cuanto a la presentación geográfica en dichos museos, predominan las categorías de nacional, regional y local frente a la supranacional.Además, hay que tener en cuenta que hay una sobrexposición de temas donde la escuela, la enseñanza y los pedagogos importantes del entorno justifican un discurso muy mediatizado por la historia de la educación. Sin embargo, también podemos apreciar el mensaje ideológico que pretende mostrar una afirmación identitaria desde el punto de vista nacional, como ocurre en Croacia, Estonia, Serbia o Portugal (Boyer, 2009: 276), pero del que no están excluidos el resto de museos que analiza. Por nuestra parte podemos añadir los casos de Latvia, Eslovenia, Italia (Macerata, Padova y Campobasso), retos similares son a los que hacen frente en Grecia (Ntinou y Vafeiadou, 2018), además de los que forman parte del presente estudio.

Por lo tanto, esta presentación del caso europeo muestra la gran diversidad de este campo en Europa y la necesidad de establecer categorías homogéneas que permitan conocer con mayor detalle las funciones que cumplen los museos pedagógicos o de la educación. En este artículo nos aproximamos al caso español con el objeto de que pueda servir como modelo de análisis para otros espacios geográficos, basándonos para ello en dos dimensiones: dependencia institucional y ubicación; y cinco categorías: el relato museístico las actividades, el fondo patrimonial, las audiencias y la gestión del museo.

\section{3 - Etapas y evolución de los museos pedagógicos en España}

En el caso de la evolución y etapas de los museos pedagógicos en España se pueden señalar dos etapas, además de un largo y profundo vacío entre ambas (Ruiz Berrio, 2012: 273 y ss). El fructífero trabajo, ya señalado, del Museo Pedagógico, como otras tantas propuestas innovadoras, se vio truncado por la victoria de las tropas franquistas en la guerra civil española y así, por medio de un decreto, publicado el 29 de marzo de 194I, el museo fue suprimido. En el 
mismo decreto se creó una institución ex-novo, el Instituto San José de Calasanz, dependiente del Consejo Superior de Investigaciones Científicas, que no continuó el trabajo de defensa del Patrimonio Histórico-Educativo iniciado 60 años atrás, pero que sí conservó todo el material bibliográfico procedente del Museo. El franquismo fue un auténtico erial en lo referente a la conservación, defensa y promoción del Patrimonio Escolar y no podemos reseñar acciones públicas ni privadas que tuvieran este ámbito como objetivo.

Esta situación ha cambiado radicalmente en los últimos 25 años y, actualmente, estamos viviendo también en España una "segunda etapa de la Museología de la educación” (Ruiz Berrio, 2012: 274). Así, promovidas por organismos diversos, están surgiendo en instituciones públicas y privadas entidades cuyo objetivo fundamental es la conservación, defensa y difusión del patrimonio histórico-educativo y se están realizando gran cantidad de jornadas, congresos y otras actividades científicas y de divulgación. Hay que subrayar asimismo que, en 2003, se creó una Sociedad Científica, la Sociedad Española para el Estudio del Patrimonio Histórico-Educativo (SEPHE) ${ }^{3}$, cuyos fines son la protección y conservación del patrimonio histórico-educativo, el estudio e investigación del patrimonio histórico-educativo y la promoción, estímulo, apoyo y difusión de las acciones relacionadas con los fines anteriormente enunciados (artículo 2 de los Estatutos de la SEPHE). Muestra de todo ello es que en estos 15 años la SEPHE ha organizado ocho Jornadas Científicas (Santiago de Compostela, 2005; Berlanga de Duero, 2007; Huesca, 2008;Vic, 20I0; Murcia, 20 I2; Madrid, 2014; Donostia-San Sebastián, 2016 y Palma de Mallorca, 2018), dos sesiones del Foro lbérico de Museísmo, además ha creado su página Web, ha realizado diez asambleas generales $y$ ha editado trece boletines informativos (los cinco últimos únicamente en soporte informático). Anualmente convoca, asimismo, el Premio Manuel Bartolomé Cossío para reconocer a las mejores acciones realizadas para la defensa y divulgación del Patrimonio Histórico-educativo.

En este momento se aprecia que el guion narrativo de los museos pedagógicos está focalizado en la historia de la educación, siendo residuales aspectos como la didáctica u otros elementos de la educación social o la educación no formal. Las causas de este fenómeno pueden explicarse por diversos factores: la desaparición de la "escuela tradicional" debido a las innovaciones pedagógicas; los cambios en los procesos de enseñanza-aprendizaje, centrados ahora en el alumnado; la emergencia de nuevos nacionalismos; el surgimiento del concepto de "cultura material escolar" (caja negra) y el nuevo papel social de los museos. En este sentido, la década de los 90 en España nos muestra un renovado interés por el patrimonio histórico-educativo, produciéndose un fenómeno de "furor museístico". La celebración de exposiciones y congresos pedagógicos, el surgimiento de grupos de investigación y la creación de nuevos museos son otras acciones que explican este fenómeno.Así, a modo de ejemplo, entre 1986 y 2004 se crearon en España 24 museos pedagógicos.

Por otra parte, la significación del carácter patrimonial de los museos continúa permanente, aunque se aprecia la incorporación de nuevos conceptos que lo enriquecen como el de "cultura material" y el de "patrimonio tangible e intangible". Finalmente, las nuevas corrientes pedagógicas nos permiten entender desde los procesos de enseñanza-aprendizaje, los procesos de apropiación cultural y la importancia de la participación para la conformación de la ciudadanía.

Como señala Linares (2012: 222), “las motivaciones que se desprenden

3 Ver http://www.sephe.org 
de los proyectos de museos sobre la educación actuales son, principalmente, la necesidad de documentar e interpretar a la educación en el pasado". Una postura nostálgica a veces, de interés histórico las más, por un lado, trata de guardar y rescatar la memoria de lo que puede llegar a borrarse y por otro lado se propone una visión más o menos crítica del pasado. Son "museos históricos" - "museos de historia" fundamentalmente. No solo porque presenten alguna cronología (Alonso Fernández, 1999) sino porque son lugares que interpretan el pasado con la intención de entender el presente y proyectar el futuro.

\section{4 - Panorama actual de los museos de la educación en España}

Para conocer la situación en España sobre el patrimonio escolar podemos adoptar dos vías, una cuantitativa y otra cualitativa. Desde el punto de vista cuantitativo, todavía resulta difícil responder con exactitud a la pregunta ¿Cuántos museos pedagógicos, escolares y de la educación existen en España? El Ministerio de Cultura posee un directorio de museos, por comunidades autónomas, que recoge los más de 1500 museos y colecciones existentes ${ }^{4}$. En este directorio, como ya hemos planteado previamente, no hay un epígrafe que recoja de manera explícita los museos pedagógicos o de la educación. Cualquier inventario o censo que se haga sobre este tipo de museos es provisional e incompleto, debido a lo apuntado previamente. Desde el punto de vista cualitativo, la situación no mejora. Para poder analizar la situación de este tipo de museos, sobre todo los dependientes de los gobiernos regionales y los universitarios, hemos procedido metodológicamente a estudiar sus características a través de los datos facilitados por las personas responsables de dichos museos, sus páginas Web y fuentes secundarias. Asimismo, hemos girado visitas a todos estos museos siguiendo los criterios que planteamos a continuación y estableciendo los indicadores que hemos utilizado para su análisis.

Para conocer la situación de los museos la primera tarea que nos hemos impuesto es realizar una tipología de este tipo de museos, analizando su relato museístico y estudiar su evolución, el tipo de conservación y las funciones que cumple. En este sentido, se pueden hacer múltiples clasificaciones de estos museos en función de varios criterios: la localización (universidades, escuelas en funcionamiento, edificios escolares históricos, complejos turísticos o secciones especiales en museos históricos); la modalidad de organización (núcleos conceptuales o temáticos (infancia o niñez), ambientaciones de aulas, centros de investigación, etc.; el público al que van dirigidos: escolar, turistas o público general e investigadores; los periodos históricos que abarcan (sistemas educativos nacionales, periodos históricos determinados (dictaduras) o la organización institucional (privados, estatales, mixtos, municipales).

En este artículo presentamos una primera clasificación en la certeza de que son todos los que están, aunque no están todos los que son. Por lo tanto, no se abordan de manera extensa, las características particulares de cada uno de los museos pedagógicos y escolares. Para abordar esta tipología hemos clasificado los museos a través de cinco categorías, en función de dos dimensiones: la ubicación y la dependencia de los mismos. Partimos de que la ubicación espacial y la dependencia de los museos son dos elementos primordiales para ordenarlos y jerarquizarlos. La ubicación espacial es importante en tanto que nos explica las dimensiones posibles de cada uno de los museos e incluso sus funciones. Asimismo, la dependencia orgánica es otro elemento importante ya que nos explica las vías de financiación, la organización interna y su grado de

4 http://directoriomuseos.mcu.es/dirmuseos/mostrarBusquedaGeneral.do 
desarrollo (Dávila y Naya, 2018). De acuerdo con estas dimensiones, podemos establecer la siguiente tipología:

I - Museos dependientes de los gobiernos regionales;

2- Museos pedagógicos universitarios;

3- Museos escolares en centros educativos no universitarios; $y$

4- Museos etnográficos o similares con temática educativa.

Otro elemento importante es que, a diferencia de otros países en España, tras la desaparición del Museo Pedagógico Nacional, no existe ningún museo nacional dedicado a la educación.

En cuanto a las cinco categorías (Álvarez, Dávila y Naya, 2017), las podemos definir así:

- Relato museístico: narración museística que dota de sentido e identidad al patrimonio histórico educativo expuesto en un museo.

- Actividades: acciones formativas o lúdicas llevadas a cabo en el propio museo, en función de la audiencia. Pueden ser exposiciones temporales, talleres pedagógicos, etc.

- Tipología patrimonial: objetos escolares, pedagógicos, infantiles, etc. que conforman el patrimonio expuesto en el museo.

- Audiencias: público visitante al que preferentemente va dirigido (escolares, adultos, universitarios, publico general)

- Gestión del museo: personal disponible, financiación y organización con el que cuenta el museo.

\section{I- Museos dependientes de los gobiernos regionales}

La característica principal de este tipo de museos es que dependen de los gobiernos regionales que los crearon. Por lo tanto, gozan de una normativa legal, de financiación recogida en los presupuestos de la Comunidad, de un personal fijo, de posibilidad de obtener material escolar de una manera sencilla, etc. Cinco son los museos que corresponden a esta categoría: el Museo Pedagógico de Galicia (Santiago de Compostela, creado en 2000), el Museo Pedagógico de Aragón (Huesca, 2006), el Centro de Recursos, Interpretación y Estudios de la Escuela (CRIEME) (Polanco, 2006), el Museo Pedagógico y del Niño de Castilla La Mancha (2010) y el Archivo y Museo de la Educación de les Illes Balears (200I).

Todos estos museos poseen un edificio específico para su alojamiento, bien sea de nueva creación o en dependencias ya existentes. Las dimensiones espaciales suelen ser considerables.

\section{Relato museístico}

- Exponen elementos que ayudan a la construcción de la identidad nacional/regional o autónoma: banderas, uniformes, etc. En el caso del MUPEGA destacan las escuelas creadas por los indianos; en el de Aragón por la formación del magisterio aragonés y en el de Castilla-La Mancha por un discurso centrado en características regionales. 


\section{Actividades}

- Actividades didácticas acomodadas a los diferentes tipos de visitante.

- Exposiciones temporales, en general, con fondos propios y aprovechando alguna efeméride o temática innovadora.

- Publicaciones propias (Cantabria publica la revista Cabás y Vidas maestras,Albacete publica Catón y Aragón editan monografías sobre temas diversos).

\section{Tipología patrimonial}

- Muestran recreaciones de aulas: tópico sin el cual no se entiende este tipo de museos.

- Presentan abundante cantidad de libros de texto y material escolar y objetos vinculados al entorno local. En el caso del Museo de les Illes Balears destaca la importancia de su archivo.

\section{Audiencias}

- $\quad$ Abiertos a todo tipo de público.

- Reiteración de objetos, señales, signos para recrear la experiencia del visitante y un discurso que gira en torno al peso de la escuela tradicional.

\section{Gestión del museo}

- $\quad$ Poseen personal estable a cargo de la administración regional.

- $\quad$ Gozan de un horario de apertura estable y amplio.

- $\quad$ Cuatro de los cinco museos están incluidos en la base de datos del Ministerio de Cultura.

- $\quad$ Todos ellos poseen página Web.

Gráfico I - Situación de los museos pedagógicos dependientes de los gobiernos regionales

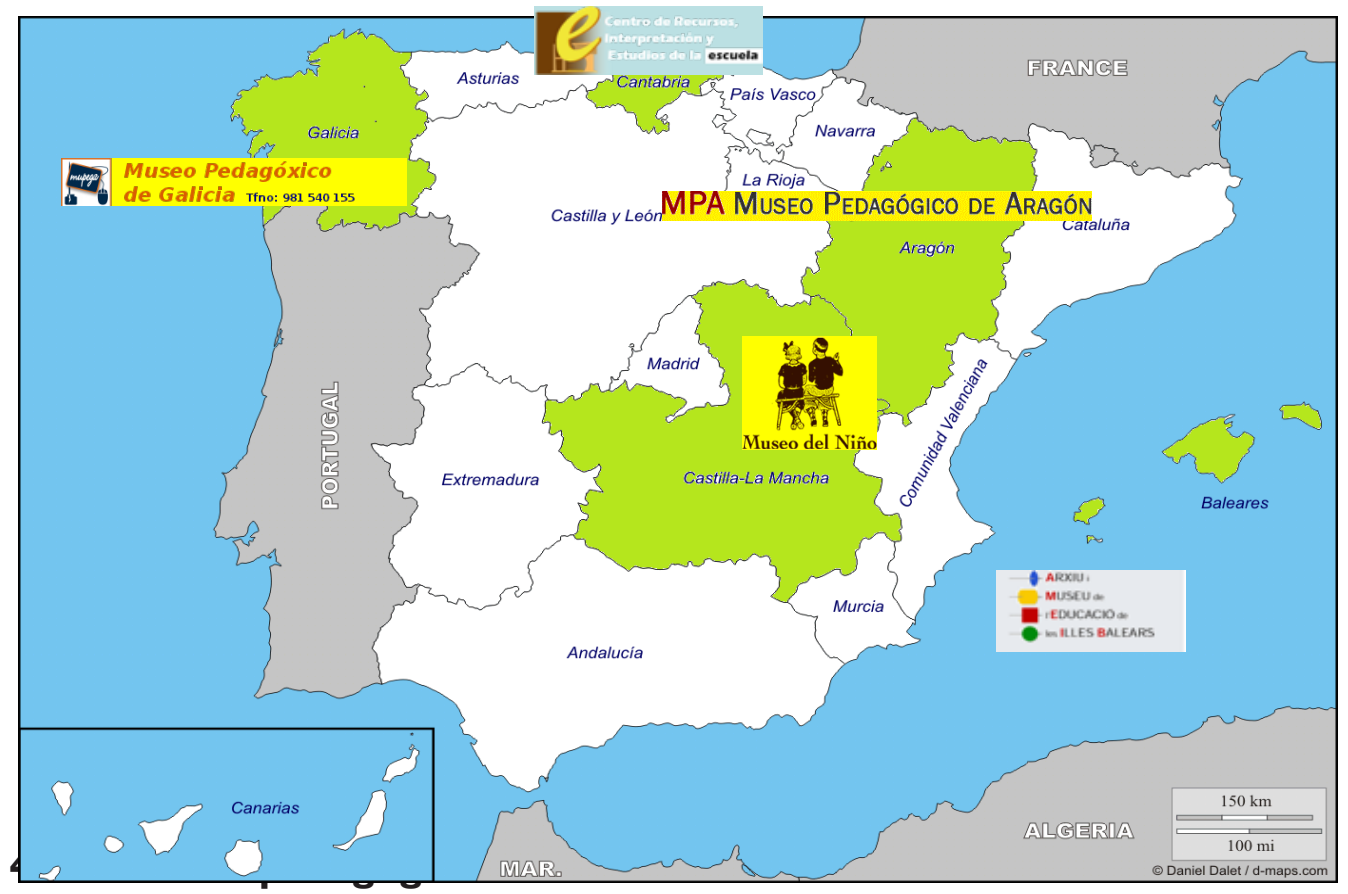


Como es conocido, en Europa existen unas 4000 instituciones de Educación Superior que albergan unos 17600 museos y/o colecciones de todo tipo (Biología, Medicina, Arte, etc.) (Lourenço, 20 I6: 62) . En España nueve universidades han puesto en marcha los siguientes museos pedagógicos:

I- Museo Laboratorio de Historia de la Educación “Manuel Bartolomé Cossío" (Madrid, 1989);

2- Museo de la Educación de la Universidad de La Laguna (La Laguna. Santa Cruz de Tenerife, 1999);

3- Centro de Estudios de la Memoria (CEME) de la Universidad de Murcia (Murcia, 2009);

4- Centro Propio Museo Pedagógico de la Universidad de Salamanca (Zamora, 20I0);

5- Museo Pedagógico de la Universidad de Huelva (Huelva, 20I I);

6- Museo Pedagógico de la Facultad de Ciencias de la Educación de la Universidad de Sevilla (Sevilla, 20I2); án, 2014) y

7- Museo de la Educación de la Universidad del País Vasco (San Sebasti-

8- Museu Pedagògic de Castelló (Castellón, 20I4), y

9- Seminario-Museo de Historia de la Escuela de la Facultad de Magisterio de la Universidad de Valencia (Valencia, en construcción).

Estos museos están ubicados en dependencias universitarias y, dentro de su estructura, tienen status diferentes. Algunos dependen de un departamento concreto o área de conocimiento (Complutense) o de una facultad (Castellon, Huelva, La Laguna, Valencia, Murcia y/o Zamora) o de grupos de investigación (Sevilla y País Vasco), no contando con personal fijo y con escasa financiación para sus actividades.

\section{Relato museístico}

No existe un relato museístico compartido. Así, el de Huelva está basado en los procesos de escolaridad, el de Salamanca en promover emociones sobre la escuela bajo el lema "sentir y pensar la escuela", el de Murcia y País Vasco tienen un discurso identitario nacional o regional. En el resto la narrativa está más basada en los objetos expuestos.

\section{Actividades}

Son museos más centrados en la investigación y la docencia y menos en la difusión, aunque cada vez se están comenzando a desarrollar más acciones en esta dirección. 
Algunos de ellos participan en actividades abiertas a la comunidad: semana de la ciencia (País Vasco, Complutense) o noche de los investigadores (Sevilla).

\section{Tipología patrimonial}

La mayoría de ellos dispone de un espacio expositivo permanente de dimensiones variables $y$, casi todos, muestran, al menos, la reconstrucción de un aula, en general tradicional.

\section{Audiencias}

Están principalmente orientados al alumnado universitario y de otras etapas del sistema educativo y a las aulas de la experiencia. En algunos de ellos hay dificultades de acceso para el público en general, ya que éste es restringido.

\section{Gestión del museo}

En algunos casos, con mayor o menos peso, tienen centros de documentación anexo al museo (País Vasco, Complutense, Salamanca, Murcia, La Laguna).

Están ubicados en dependencias universitarias.

Tienen estatus diferentes: algunos dependen de departamentos universitarios o áreas de conocimiento (Complutense) o de una facultad (Castellón, Sevilla, Huelva, La Laguna, Valencia, Murcia y/o Zamora) o de grupos de investigación (País Vasco). actividades.

No cuentan con personal fijo y disponen de escasa financiación para sus

Se ha producido un proceso de especialización en función del material obtenido: memorias de prácticas de maestros (Complutense o Castellón), cuadernos escolares (Salamanca, País Vasco); material científico (Murcia); memorias escolares (País Vasco); manuales escolares, Memorias de prácticas y libros de texto (Huelva, Complutense, País Vasco, Salamanca, La Laguna).

De manera complementaria a lo que estamos diciendo podemos señalar una posible subcategoría de los museos universitarios como son los museos pedagógicos virtuales, ubicados, por su gestión en sedes universitarias. Los más destacables en el caso español son dos: el Museo universitario Virtual de Pedagogía de la Universidad deVic (MUVIP) (Vic, Barcelona, 2006) y el Museo Virtual de Historia de la Educación (MUVHE) (Murcia, 2009). Este tipo de museos no se puede confundir con las páginas Web de los propios museos físicos. Hay que destacar que son un instrumento de enseñanza sin que dispongan de patrimonio histórico-educativo tangible. 
Gráfico 2.- Situación de los museos de la educación dependientes de las universidades

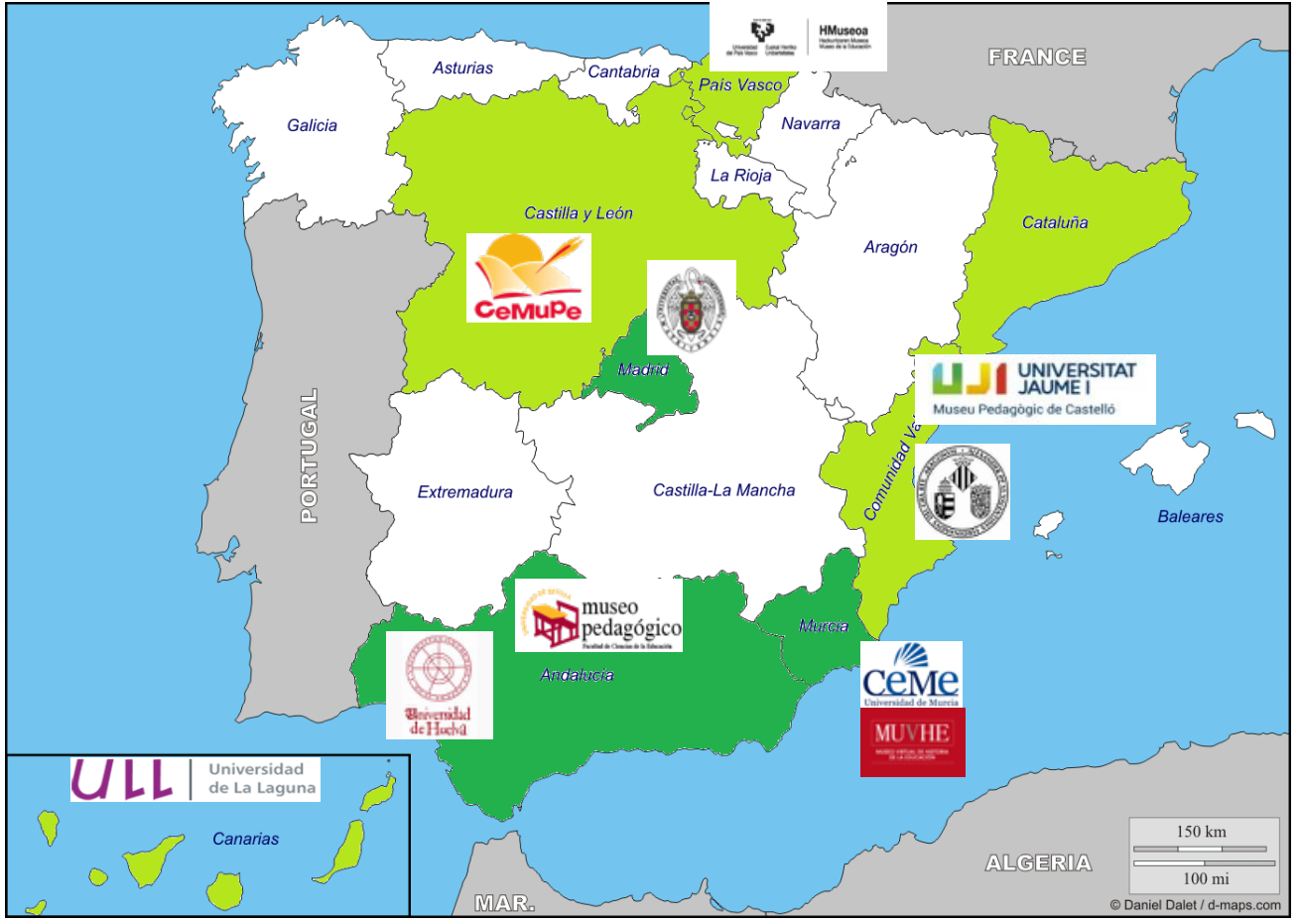

\section{3 - Museos escolares en centros educativos no universitarios en fun- cionamiento}

Los museos denominados pedagógicos han solido estar relacionados con un discurso museístico nacionalista u orientado a la formación pedagógica, mientras que los museos escolares se han construido históricamente dentro de las propias escuelas, como un espacio que actuaba como dispositivo didáctico para apoyar las clases. Los museos escolares, en general, como hemos planteado previamente, tenían estas características: recogían colecciones de flora, fauna y minerales, modelos para las clases de anatomía, la historia natural, etc., y su objetivo era ser utilizados como material de experimentación. Estos museos se nutrían de aportaciones del propio alumnado, de los docentes o de compras diversas. Este tipo de museos dinámicos continúa existiendo, cumpliendo parecidas funciones e incorporando otro tipo de objetos creados por los propios alumnos.

Dentro de esta categoría incluimos también las colecciones de materiales didácticos utilizados en los centros de enseñanza secundaria, tanto públicos como privados y que, en la mayoría de los casos, se adquirían a casas comerciales. Los denominados "Institutos Históricos" han reconvertido este material en museos que permanecen en el propio centro, otorgándoles un plus de identidad y de distinción social y escolar. Un ejemplo de ellos lo podemos ver en los Instituto Isabel la Católica de Madrid, el Alfonso X el Sabio de Murcia, etc. Estos centros habitualmente están localizados en las capitales de provincia y han sido, hasta la actualidad un referente educativo, sobre todo cuando la sede de la universidad estaba en una provincia diferente.

Por lo que respecta a los innumerables museos escolares sitos en centros educativos de primaria, tanto urbanos como rurales, se aprecia que se incorporan a la protección del Patrimonio Histórico-Educativo a través de la 
reconstrucción, en general, de un aula antigua. En función de la disponibilidad de material estas aulas están ornamentadas con objetos diversos (láminas, globos terráqueos, torsos humanos, libros de texto, cuadernos, reglas, etc.). A veces sin una exactitud en representar un espacio que reviva el aula que pretenden representar.

No existe un censo que nos permita saber cuántos museos de este tipo existen, pero podemos afirmar que son muy numerosos y posibilitan una educación patrimonial cada vez más necesaria desde los primeros años. Dadas sus características, la mayor dificultad de estos museos es el acceso a los mismos, debido a la falta de información sobre su existencia y a que no disponen de personal dedicado a esta tarea, que suele recaer en los profesores del centro.

\section{Relato museístico}

En algunos casos son utilizados como recurso docente por parte de centros escolares en activo situados en las cercanías.

Hay diferentes grados de profundidad en el relato dependiendo de que la gestión sea más o menos profesional.

\section{Actividades}

Habitualmente no suelen desarrollar actividades extraordinarias.

Número de actividades reducidas en torno al material expuesto.

\section{Tipología patrimonial}

Habitualmente tan sólo reproducen un aula escolar, laboratorio de la época o lugares de tránsito.

El objetivo es reproducir los espacios escolares de épocas pretéritas.

\section{Audiencias}

Acceso restringido.

\section{Gestión del museo}

La mayor dificultad es el acceso a los mismos, debido a la falta de información sobre su existencia y a que no disponen de personal dedicado a esta tarea, tarea que suele recaer en los profesores del centro.

Suelen estar gestionados por el propio centro escolar o por antiguos docentes.

\section{4 - Museos etnográficos o similares con temática educativa}

Los museos que podríamos incluir dentro de esta categoría son muy variados. Podemos distinguir, principalmente, dos tipos de museos: I.- los que están ubicados en centros escolares que no están en funcionamiento y que muestran un aula tradicional, situados habitualmente en zonas rurales, y 2.- un espacio dedicado a la escuela ubicado en museos etnográficos.

Por lo que respecta a los primeros, suelen estar gestionados, bien por el municipio o por una asociación de amigos o fundaciones privadas. Suelen ser 
un reclamo turístico que revitaliza las actividades del entorno en que están situados. En algunos casos pueden ser utilizados como museo para otros centros escolares situados en las cercanías o, en otros, son escuelas que rinden homenaje a un personaje célebre, en general indiano, que hizo algún tipo de aportación para el desarrollo educativo de la comarca o del pueblo. Como hemos dicho previamente, se trata de museos que, en muchas ocasiones, tan sólo reproducen un aula escolar y el objetivo es plasmar una escuela nostálgica y vinculada a la evolución histórica de la enseñanza en el entorno.

Con relación a los segundos, algunos museos etnográficos, desde una perspectiva generalista, han incluido en su diseño museístico un espacio donde, en general, se representa un aula de las mismas características que el anterior. El discurso que sustenta la presencia de esta aula está, en algunos casos, bien argumentado, al incluirlo dentro de las actividades infantiles, pero en otros casos es una mera reconstrucción espacial que sustenta un tipo de discurso sobre los espacios que habitualmente conformar un pueblo o una ciudad.

En estos momentos la Sociedad Española para el Estudio del Patrimonio Histórico-Educativo ha iniciado la catalogación de los diferentes museos escolares (Red MEINPHE) , pedagógicos, escolares o de la educación que existen en España, los datos de los que disponemos son, de momento, desiguales entre las diferentes provincias españolas ${ }^{5}$, pero esperamos que esta tarea de sus frutos en un futuro cercano. Es por ello que, todavía, no podemos ofrecer una cartografía completa de la situación de este tipo de museos en España, ya que los datos son incompletos y difíciles de obtener.

\section{Relato museístico}

En algunos casos, se trata de escuelas que rinden homenaje a un personaje célebre de la localidad que creó un patronato escolar o que hizo algún tipo de aportación para el desarrollo educativo de la comarca o del pueblo.

Hay diferentes grados de profundidad en el relato dependiendo de que la gestión sea más o menos profesional.

\section{Actividades}

Número de actividades reducidas, pero muy consolidadas.

De carácter más divulgativo y lúdico.

\section{Tipología patrimonial} infantiles.

Habitualmente tan sólo reproducen un aula escolar o espacios de juegos

El objetivo es plasmar una escuela nostálgica.

\section{Audiencias}

Suelen ser un reclamo turístico que revitaliza las actividades del entorno en que están situados.

Públicos diversos e imprevisibles.

5 Los primeros resultados de esta cartografía se pueden consultar en https://sephe.org/red-mein-phe/ 


\section{Gestión del museo}

Suelen estar gestionados por el municipio, por una asociación de amigos o por fundaciones privadas.

\section{5 - Conclusiones}

La situación actual de los museos de la educación en España, sean pedagógicos o escolares, nos ha permitido rastrear los antecedentes más inmediatos de estos museos, abordando, en una primera parte, aspectos conceptuales relativos a la definición de museo pedagógico y del museo escolar y el contexto europeo dentro del cual deberíamos analizar el caso de España. La realización de una incompleta cartografía de todos estos museos nos ha permitido acercarnos a unos indicadores (dimensiones y categorías) que nos permitan cierta comparación entre los mismos, resaltando la vitalidad que se puede constatar en las últimas tres décadas, sobre todo los museos pedagógicos universitarios y los dependientes de los gobiernos regionales. Así, podemos destacar los siguientes resultados por cada una de las categorías utilizadas:

I- Relato museístico, en el que se ha puesto de manifesto el contraste de los modelos de museos analizados, en cuanto a sua narración.

2- Actividades, se aprecia, asimismo que la dependencia institucional permite un mayor o menor desarrollo de las mismas, debido, sobre todo, a la existencia de personal encargado de las mismas.

3- Tipología patrimonial, en el que también se pone de manifiesto la riqueza histórico-educativa de los objetos expuestos en cada uno de esos museos.

4- Audiencia, hay que valorar positivamente el deseo de apertura a nuevos públicos que subyace en cada uno de ellos, pues se entiende que la búsqueda de nuevas audiencias es un objetivo claro para dinamizar la vida de los museos $y$, consecuentemente, favorecer la participación ciudadana.

5 - Gestión del museo, este indicador es la pieza clave que nos permite entender el resto de indicadores, ya que la organización institucional y el grado de dependencia de los museos favorece una gestión más profesional.

La existencia en España de este conjunto de museos de la educación da cumplida cuenta, por su extensión territorial y agentes implicados, de una dinamicidad ejemplar y de los retos a los que se enfrentan en un futuro, como son la protección y difusión del patrimonio histórico-educativo y la implicación de la sociedad en esta tarea. En el horizonte de retos posibles está sin duda la creación de una cartografía que nos permita conocer mejor la situación de los museos de la educación. El valor mayor de esta aportación es el de señalar unos criterios e indicadores que puedan ser válidos para analizar cualquier tipo de museo, completando así el análisis de los museos de la educación. No obstante, somos conscientes de que se trata de una tarea en proceso de realización. Al igual que se ha hecho en Francia, con la Red que está constituyendo la Association des Amis du Musée National de l'Éducation ${ }^{6}$, el objetivo de este artículo ha sido es favorecer la realización de un inventario que ha puesto en marcha en España la Sociedad Española para el Estudio del Patrimonio Histórico Educativo ha comenzado a organizar la Red MEHINPE, con la que pretende completar esta cartografía. 


\section{Referências}

ALONSO FERNÁNDEZ, Luis. Museología y museografia. Buenos Aires: Ediciones del Serbal, 1999.

ÁLVAREZ, Pablo (Coord.). Los Museos Pedagógicos en España: entre la memoria y la creatividad. Gijón,TREA y Editorial Universidad de Sevilla, 2016.

ÁLVAREZ, Pablo; DÁVILA, Paulí \& NAYA, Luis M. Education museums: historical educational discourse, typology and characteristics. The case of Spain, Paedagogica Historica, 53:6, 2017, 827-845, DOI: 10.1080/00309230.2017.139299I

ASCENZI, Anna; BRUNELLI, Marta y MEDA, Juri. Représentation du passé scolaire dans les musées de l'école en Italie. In Première rencontre francophone des musées de l'école,Actes Rouen 2016,VV.AA. Rouen,Amis des musées de l'école et du patrimoine éducatif, pp. 89-103.

BOYER, Myriam. Les collections et les muséographies des musées de l'école et de l'éducation en Europe. PhD diss., Centre d'histoire des techniques et l'environement, Paris, 2009.

BOYER, Myriam. Les musées de l'école et de l'éducation : un champ muséal quantitativement significatif mais difficile à cerner, Muséologies 52, p. 104-129, 2011.

CARRILLO, Isabel; COLLELLDEMONT, Eulalia; MARTÍ, Jordi y TORRENTS, Jacint Los museos pedagógicos y la proyección cívica del patrimonio educativo. Gijón, TREA, 2012.

DAVILA, Paulí y NAYA, Luis M. Constitution, conservation et valorisation du patrimoine scolaire en Espagne. in Première rencontre francophone des musées de l'école, Actes Rouen 20 16,VV.AA. Rouen, Amis des musées de l'école et du patrimoine éducatif, pp. 77-88.

ESCOLANO, Agustín (ed.) La cultura material de la escuela. En el centenario de la Junta para la Ampliación de Estudios 1907-2007 Berlanga de Duero: CEINCE, 2007. ESCOLANO, Agustín y HERNÁNDEZ, J. Mª L La memoria y el deseo: cultura de la escuela y educación deseada. Valencia,Tirant lo Blanch, 2002.

FATALOT, Albert. Musées pédagogiques. In BUISSON, Ferdinand Dictionnaire de Pédagogie et d'instruction Primaire. Pris, Librarire Achete, I888, p. I892-I889.

GARCÍA DEL DUJO,Angel. Museo Pedagógico Nacional. Desarrollo histórico y contribuciones a la educación española contemporánea, I882-194 I. Salamanca, Universidad de Salamanca, 194, 1984.

GARCIIA DEL DUJO,Angel. El Museo Pedagógico Nacional: otra manera de ver la educación y la pedagogía, Revista de Ciencias de la Educación, n² 231, pp. 279$289,2012$.

JUAN, Víctor ed., Museos Pedagógicos. La memoria recuperada. Huesca: Gobierno de Aragón, Museo Pedagógico de Aragón, 2008.

JULIA, Dominique,A Cultura Escolar como Objeto histórico. Revista brasileira de história da educação $\mathrm{n}^{\circ} \mathrm{I}$ jan./jun, pp. 9-43, $200 \mathrm{I}$.

LINARES, Cristina. Educar con los objetos. Museos pedagógicos en la historia de la educación argentina. Buenos Aires, Universidad Nacional de Luján, 2012.

LÓPEZ, Ramón. La escuela por dentro. Perspectivas de la cultura escolar en la España del siglo XX.Valencia: Universitat de Valencia, 200I.

LOURENÇO, Marta. Museus e coleções universitárias na Europa e América Latina: um panorama diverso. In Dávila, Paulí y Naya, Luis M.: Espacios y Patrimonio Histórico-Educativo. Donostia-San Sebastián Erein, Pp. 6I-77, 2016. Accesible en http://hdl.handle.net/I08/0//85 I2

LUZURIAGA, Lorenzo. Diccionario de pedagogía. Buenos Aires, Losada, 1960. 
MARTÍN, Bienvenido. El museo pedagógico de la Universidad de Salamanca, Foro de educación, 9, 2007, pp. 349-358, 2007.

MEDA, Juri. Musei della scuola e dell'educazione, History of Education and Children's Literature, 2, p. 489-50I, 2010.

MEDA, Juri y BADANELLI, Ana M. La historia de la cultura escolar en Italia y en España: balance y perspectivas. Macerata: Edizioni Università di Macerata, 2013.

MIEUSSENS, Michel.Vers un réseau des musées de l'école et du patrimoine éducatif, in Première rencontre francophone des musées de l'école, Actes Rouen 2016, VV.AA. Rouen, Amis des musées de l'école et du patrimoine éducatif, pp. 29-50. MOGARRO, M $^{\mathrm{a}}$ Joao ed. Educaçao e Patrimonio Cultural: Escolas, Objetos e Práticas Lisboa: Ediçoes Colibri/Instituto de Educaçao, 2015.

MORENO, Pedro Luis. La Historia de la Educación como disciplina y campo de investigación: renovación historiográfica, patrimonio y educación, in El largo camino hacia una educación inclusiva. La Educación Especial y Social del siglo XIX a nuestros días, ed. Reyes Berruezo and Susana Conejero, Pamplona: Universidad Pública de Navarra,Vol. III, 2009.

MORENO, Pedro Luis. La historiografía del patrimonio educativo en España: un balance crítico, Educar em Revista, 58, p. 87-I02, 2015.

NTINOU, Magdalini andVAFEIADOU, Evgenia. Museum of Education: challenges and successes in a Greek University Museum, University Museums and Collections Journal, Vol I0, pp. 77-83, 2018.

PEÑA, Vicente y otros. Os museos da educación en Internet. Santiago de Compostela: Xunta de Galicia, Conselleria de Educación e Ordenacion Universitaria, MUPEGA, 2004.

RUIZ BERRIO, Julio. El museísmo pedagógico en el mundo: pasado, presente y perspectivas de futuro. En I Foro Ibérico de Museísmo pedagóxico. $O$ museísmo pedagóxico en España e Portugal: itinerarios, experiencias e perspectivas. Coordinación Vicente Peña Saavedra, Santiago de Compostela: Xunta de Galicia-MUPEGA, pp. 55-72, 2003.

RUIZ BERRIO, Julio. Historia y museología de la Educación. Despegue y reconversión de los museos pedagógicos", Historia de la Educación. Revista Interuniversitaria, 25, p. 27I-290, 2006.

RUIZ BERRIO, Julio. El patrimonio histórico-educativo. Madrid, Biblioteca Nueva, 2010.

RUIZ BERRIO, Julio. Presentación I Jornadas de Patrimonio Histórico-Educativo". Revista de Ciencias de la Educación, 23 I-132, Monográfico dedicado a: Pensar y sentir la escuela: I Jornadas de Patrimonio Histórico-Educativo del CeMuPe, pp.273278, 2012.

SÁNCHEZ SARTO, Luis. Diccionario de Pedagogía. Madrid, Labor, 1936.

XANDRI PICH, José. Museos y exposiciones escolares. Madrid, Revista de Pedagogía, 1927. 